\title{
MATERIAIS E PRÁTICAS NO ENSINO DE PORTUGUÊS PARA ESTRANGEIROS
}

\section{TEACHING MATERIALS AND PRACTICES IN PORTUGUESE CLASSES FOR FOREIGNERS}

\section{MATERIALES Y PRÁCTICAS EN LA ENSEÑANZA DEL PORTUGUÉS PARA ESTRANJEROS}

(iD) Aluízio Lendl ${ }^{1}$

(D) Marta Lúcia Cabrera Kfouri ${ }^{2}$

(iD) Rickison Cristiano de Araújo Silva ${ }^{3}$

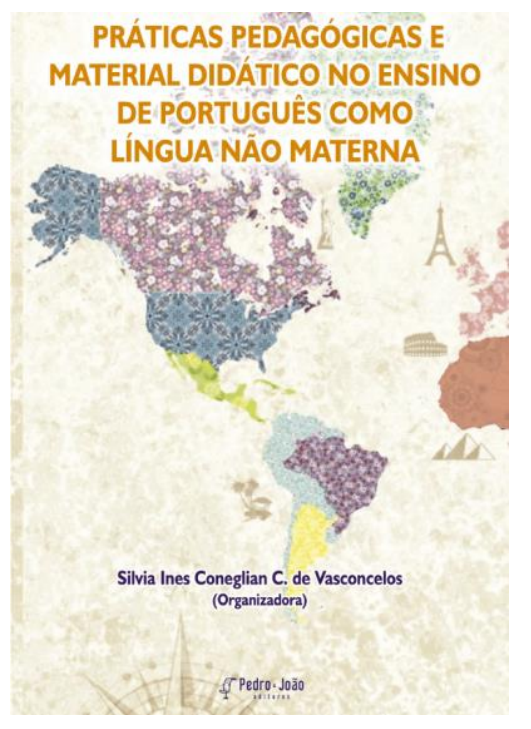

VASCONCELOS, Silvia Ines Coneglian Carrilho de (Org). Práticas pedagógicas e material didático no ensino de português como língua não materna. São Carlos, SP: Pedro \& João Editores, 2019.

\footnotetext{
${ }^{1}$ Doutor em Letras pela Universidade do Estado do Rio Grande do Norte (UERN). Professor de Linguística na Universidade Estadual do Ceará (UECE/FECLI). E-mail: aluizio.lendlbezerra@uece.br

${ }^{2}$ Mestre e Doutora em Estudos Linguísticos pela Universidade Estadual Paulista “Júlio de Mesquita Filho", UNESP, campus de São José do Rio Preto, SP, Brasil, onde atua como professora Assistente Doutora junto ao Departamento de Educação. Email: marta.kfouri@unesp.br

${ }^{3}$ Doutorando em Linguagem e Ensino pela Universidade Federal de Campina Grande (PPGLE/UFCG). E-mail: rickison_critiano@hotmail.com
}

Recebido em: 19/03/2021

Aprovado em: 16/04/2021 
A organizadora da obra em questão, "Práticas pedagógicas e material didático no ensino de português como língua não materna", é Silvia Ines Coneglian Carrilho de Vasconcelos, graduada em Letras pela Universidade Paulista, mestre em Língua Portuguesa pela PUC-SP, doutora em Linguística Aplicada e Estudos da linguagem pela PUC-SP e Pós-doutora em Linguística Aplicada pela UNICAMP e em Letras pela UPMackenzie. Tem experiência na área de Linguística, com ênfase em Linguística Aplicada, atuando nos seguintes temas: discurso, mídia, ensino, escrita acadêmica, pesquisas qualitativas e ensino de língua portuguesa como línguas materna e estrangeira. Foi coordenadora acadêmica do Programa CAPES/MEC/UFSC/INFORDEP/PQLP/Timor Leste para Língua Portuguesa. Atualmente, é professora do Departamento de Língua e Literatura Vernáculas da Universidade Federal de Santa Catarina (UFSC), onde atua também como professora do Mestrado Profissional em Letras- PROFLETRAS.

A temática da obra produzida é recorrente nos trabalhos de Silvia, sendo, inclusive, tema de seu atual projeto de pesquisa. Na coletânea, financiada pela CAPES- Coordenação de Aperfeiçoamento de Pessoal de Nível Superior, a organizadora e também autora reúne dez capítulos, distribuídos em duas partes - Práticas Pedagógicas e Problematizando o Material Didático - escritos por quinze estudiosos de diferentes contextos educacionais: Universidade Federal de Santa Catarina (UFSC), Pontifícia Universidade Católica de São Paulo (PUC/SP), Universidade do Estado do Maranhão (UEMA), Universidade Nacional de Rosário (Argentina) e Universidade de Princeton, New Jersey (EUA). O objetivo dos autores é apresentar um panorama de projetos e pesquisas de intervenção em práticas pedagógicas em torno do ensino de português em enfoques atuais diversos (língua não materna, segunda língua, língua de herança, língua adicional ou de acolhimento, dentre outras). Nesse escopo, questões ideológicas, políticas e teóricas são discutidas, a fim de proporcionar o debate e uma possível reconstrução teórico-prática na área, sendo, por isso, uma obra sem dúvida atrativa para o público acadêmico que atua no contexto de ensino de língua portuguesa, tratada no livro como não-materna, no intuito de abrir o leque de contribuições reunidas para a discussão, porém, sem descaracterizar o contexto de investigação e análise descrito em cada capítulo.

Sendo assim, na Parte I, Práticas Pedagógicas, encontramos sete dos dez capítulos que leremos na coletânea, cujo enfoque é o compartilhamento de pesquisas com enfoque na interação social de estrangeiros por meio do ensino-aprendizagem de português como língua não materna, bem como a contribuição dessas ações para a inserção social desses aprendizes em novos contextos de vida. É interessante notar que as pesquisas quase sempre dialogam entre si, partindo da implementação de diferentes estratégias investigativas para públicos semelhantes, no intuito de oferecer uma compreensão mais significativa da 
língua portuguesa e suas manifestações culturais, em busca do acolhimento e do pertencimento emocional, social e linguístico dos estrangeiros participantes.

O capítulo "Africanidades e saudades: um encontro entre Haiti e Brasil por meio da música brasileira", é de autoria de Aline Cristina Pereira, professora de língua portuguesa na rede pública estadual na cidade de Joinville (Santa Catarina), e de Edna Kurisini Diatel, professora de língua portuguesa e literatura de Educação Básica da rede pública estadual na cidade de Florianópolis (Santa Catarina), ambas mestrandas do PROFLETRAS-UFSC. O texto se inicia com o olhar das autoras para as ruas de Joinville, uma cidade industrial catarinense que encara com olhos de racismo expresso em pichações como "Aqui não é o Haiti" os haitianos que, a partir do terremoto enfrentado naquele país em 2012, passaram a habitar a cidade, formando uma população de cerca de 2000 refugiados no local. Após uma breve contextualização socioeconômica da realidade dos cidadãos haitianos no estado de Santa Catarina e no Brasil, Aline e Edna dirigem-se aos profissionais da linguagem, em especial aos de língua portuguesa, chamando-lhes atenção para a necessidade de se voltarem às demandas metodológicas em torno do português como língua não materna para falantes de outras línguas, em busca de capacitar esses cidadãos para uma nova vida social por meio da linguagem, em um país longínquo para eles, o Brasil. Assim, o projeto de pesquisa a que se dedicam tem como objetivo o ensino de português língua adicional (PLA) a haitianos em contexto joinvilense, por meio de uma abordagem comunicativa de viés cultural e de pertencimento emocional, especialmente em torno de reflexões sobre racismo, intolerância e exclusão social. O encaminhamento das questões se deu com base em teóricos como Bakhtin, Vygotsky, Almeida Filho, Dolz e Schneuwly, Rojo entre outros nomes de referência, por meio do trabalho primoroso com o gênero musical samba-rock, que é o samba interpretado por uma guitarra, para enfocar a temática de "africanidades". O artista escolhido foi Jorge Ben Jor em sua música “Zumbi”, na qual o músico retrata com genialidade a saga dos negros vindos da África para serem escravizados nas lavouras de cana do Brasil. Outra obra de arte levada para a sala de aula investigada pelas autoras foi o forró “Asa Branca”, de Luiz Gonzaga, ícone da música nordestina brasileira, sendo uma das canções mais populares do Brasil e, por isso, escolhida para a temática "saudades". A escolha pelo material musical para o desenvolvimento do plano de ação permitiu, como previram as autoras e se concretizou nas atividades, o trabalho com a linguagem autêntica e interdiscursiva e de conhecimento de mundo, manifestados em expressões idiomáticas, gírias e pronúncias regionais, bem como a possibilidade de discussões acerca da presença marcante do negro no Brasil e das questões sociais que enfrentam, promovendo o que as autoras caracterizaram como "um encontro legítimo entre Haiti e Brasil".

O capítulo seguinte, intitulado "Experiência pedagógica com expressões idiomáticas em material didático do português brasileiro como língua adicional”, tem como autoras Maria Denize Carniel da Silva, 
professora de língua estrangeira (Inglês) e de língua portuguesa dos anos finais do ensino fundamental e do ensino médio na rede pública estadual de Santa Catarina, e Michelli Marchi Oss-Emer, professora de língua portuguesa na rede pública municipal de Blumenau (Santa Catarina) e na rede pública estadual de Santa Catarina. Ambas são também mestrandas do PROFLETRAS da UFSC. No capítulo, as autoras abordam os resultados de uma pesquisa-intervenção desenvolvida com alunos haitianos de uma escola municipal de Blumenau (SC), cujo enfoque eram “expressões idiomáticas”. Para tanto, aplicaram ao contexto um material didático de caráter intercultural elaborado por ambas, voltado ao ensino de português língua adicional (PLA), cujo objetivo era justamente proporcionar a compreensão e interação de estudantes estrangeiros de PLA por meio do estudo de expressões idiomáticas utilizadas por falantes brasileiros, bem como motivar esses estudantes a verbalizarem expressões de sua própria língua-cultura, enriquecendo o material de estudo. Além disso, as professoras-pesquisadoras buscavam melhorar a compreensão de tais expressões, contribuindo para um melhor entendimento entre brasileiros e haitianos, em contexto de ensino público estadual. A pesquisa interventiva foi delineada com base nos pressupostos teóricos sobre sequência didática de Dolz e Schneuwly e Bakhtin. Já o levantamento de expressões idiomáticas foi baseado em Cascudo, cuja obra em torno da cultura e do folclore brasileiros tem reconhecimento internacional, e em Pimenta, tendo sido trabalhadas expressões em ilustrações muito marcantes da língua-cultura brasileira, tais como "a sete chaves", "custar os olhos da cara", "maria-vai-com-as-outras", "pé rapado", "arrancarabo", "cheio de nove horas", "tirar o cavalo da chuva", "puxa-saco", entre outras tão representativas em âmbitos histórico e linguístico-cultural, consideradas em situação de uso comunicativo por mídia digital whatsapp. A partir do reconhecimento de que a inserção de alunos estrangeiros nas escolas brasileiras como algo substancial e crescente gera dificuldades aos professores no trabalho com a língua portuguesa, as autoras concluem que as atividades realizadas por meio do material didático proporcionaram aos alunos haitianos o conhecimento mais elucidado de um recurso comunicativo muito comum aos brasileiros, que é o uso de expressões idiomáticas, acreditando terrem atingido seu objetivo de pesquisa quanto a minimizar falhas na interação e a possibilitar que o material produzido aprimore o ensino-aprendizagem de PLA em outros contextos.

No capítulo "Culinária brasileira no material didático de português como língua adicional”, as autoras, também mestrandas do PROFLETRAS da UFSC, são Fabiana de Fátima Aparecida de Oliveira, professora de língua portuguesa na rede pública municipal de ensino de São José (Santa Catarina) e Jéssica Mendes da Silva Rodrigues, que atua como professora de língua portuguesa da rede pública estadual de ensino na cidade de Pinheiro Machado (Rio Grande do Sul). O capítulo é também resultado de uma pesquisa-intervenção que consistiu em analisar a aplicação de um material didático elaborado especialmente para o uso no ensino de português língua adicional (PLA), destinado a mães haitianas 
refugiadas em Florianópolis, Santa Catarina. O conteúdo didático eram os ingredientes e os pratos típicos da culinária brasileira organizado por regiões do Brasil, tendo por apoio teórico e metodológico as contribuições de Dolz, Schneuwly, Rojo, Moita Lopes, Nicolaides, Lima e Reis e Thomé-Williams, para quem a alimentação e a culinária são temáticas de acolhimento. Nesse sentido, as próprias autoras produziram os alimentos e os fotografaram para o livro, transformando-os nas atividades pedagógicas previstas. A leitura do percurso metodológico das aulas nos leva a perceber o trabalho intercultural na descrição das práticas alimentares nas regiões do Brasil, bem como de sua caracterização étnica e geográfica. Além disso, fica explícita a identificação das mães haitianas com o conteúdo trabalhado, motivando-as a descrever alguns pratos, época de cultivo de ingredientes e bebidas da culinária de seu país, dando significação ao trabalho intercultural e dialógico. O planejamento com base nas necessidades cotidianas das alunas e em seu conhecimento de mundo parece ter sido o fator fundamental para o resultado bem-sucedido do trabalho desenvolvido, gerando resultados positivos tanto em relação à língua-cultura quanto à instauração de interações mais significativas entre as professoras, autoras da investigação, e as alunas haitianas.

O capítulo "Jogos lúdicos no ensino de português como língua adicional para mães haitianas: socialização e aprendizagem”, tem como autoras Aline Suzana de Freitas Vaz, professora de língua portuguesa no estado de Santa Catarina, e Maria Clara Dias da Cruz, professora do EJA da rede pública municipal de Florianópolis (Santa Catarina), também cursando mestrado no PROFLETRAS da UFSC. No capítulo, as autoras registram o resultado de uma pesquisa interventiva com mães haitianas de crianças em idade pré-escolar e escolar, vivendo em situação de refúgio em Florianópolis, Santa Catarina. A proposta investigativa deu-se a partir da aplicação de um material didático de português língua adicional (PLA), a partir das experiências de aprendizagem da língua pelas referidas mães, ou seja, levando em conta sua contribuição para a elaboração de um material de ensino mais pertinente e significativo para a comunidade em que as haitianas estavam inseridas, tendo em vista sua integração sociocultural e a de seus familiares, por meio da linguagem. O ponto de inspiração do trabalho de intervenção foram os importantes estudos do sociólogo brasileiro Florestan Fernandes, que investigou de que maneira as brincadeiras de crianças de Bom Retiro, bairro popular de imigrantes italianos na cidade de São Paulo, na década de 1940, contribuía para a socialização dos familiares adultos, bem como os estudos sobre a sedução como estratégia para aprender línguas, de Narezzi. Assim, as autoras elaboraram um material didático baseado em brincadeiras infantis ensinadas em português como forma de envolver as mães haitianas na interação lúdica com seus filhos, facilitando tanto a aprendizagem de PLA como a integração social entre as mães e a escola. Estudos de autores como Bizon, Moita Lopes, Leffa e Irala, Vygotsky, Bakhtin e outros, que concebem a língua enquanto discurso constituído na prática social, constituem o aporte teórico da pesquisa desenvolvida por 
Aline e Maria Clara, que têm como objetivo maior o compromisso com a investigação sobre a aprendizagem de PLA diante das demandas sociais constituídas historicamente, sendo a língua um elemento de democratização e de reterritorializações, valendo-se, para tanto, da metodologia da transposição didática, de Rojo. A concepção de família apresentada por Bakhtin, como questão sócio-histórica, ou seja, cujo valor social só se constrói em contexto, é a que alicerça o trabalho aqui exposto. Dessa maneira, atividades lúdicas como os jogos de "amarelinha" e "mamãe posso ir" foram utilizadas como material didático para abordar conceitos de socialização e aprendizado, vocabulário constituinte das brincadeiras e leitura das regras do jogo como forma de socialização, em um processo de interação intercultural, já que, além de aprenderem, as mães também ensinaram às professoras jogos e gestuais típicos das brincadeiras de suas regiões de origem. A contribuição e a gentileza das mães haitianas foram fatores de êxito da atividade, gerando resultados positivos para a investigação, desenvolvida em um programa de pós-graduação profissionalizante, que tem como foco a melhora dos índices escolares e a diluição de problemas educacionais, por meio do olhar social dos participantes. As autoras destacaram com notável entusiasmo os desdobramentos do trabalho realizado, que gerou oficinas e textos como os desta coletânea, além da possibilidade de inspirar novas pesquisas em outros ambientes de alunos estrangeiros em contexto de PLA.

O capítulo seguinte, intitulado "Desconstrução do estereótipo da mulher brasileira com alunos estrangeiros: Uma proposta de intervenção nas aulas de Português como Língua Adicional" foi desenvolvido também pelas mestrandas do PROFLETRAS Maria Gabriela Abreu e Thaís Gonçalves Martins. Fruto de um projeto de pesquisa-intervenção que culminou na elaboração e aplicação de um material didático, no curso extracurricular de línguas da Universidade Federal de Santa Catarina (UFSC), voltado para estudantes estrangeiros de Português como Língua Adicional (PLA), de nível avançado, com a temática voltada para os estereótipos acerca da imagem da mulher brasileira no estrangeiro. O interesse pelo tema desenvolvido no material didático: a representação sexualizada das mulheres, realizada historicamente na mídia e nas produções audiovisuais, se deu pela oportunidade de levar para o processo de ensino-aprendizagem um tema polêmico, conforme sinalizam as autoras, em que há possibilidades de desenvolver interações culturais a partir de uma realidade que ainda perpassa nossa sociedade. Para tanto, a partir de uma perspectiva interculturalista, a investigação foi realizada com objetivo de desenvolver a competência comunicativa dos estudantes de PLA, bem como a desconstrução do estereótipo cultural, criado por muitos estrangeiros, a respeito da imagem das mulheres brasileiras, através de atividades que promoviam o debate e a reflexão sobre a temática. Dessa maneira, participaram dois alunos estrangeiros, um italiano de 27 anos e um japonês de 28 anos, cujas identidades foram preservadas. A proposta didática foi composta de atividades orais que levaram os participantes a expor suas visões sobre as mulheres brasileiras e de que forma os estereótipos eram feitos e compartilhados em seus países de origem, em busca 
de uma reflexão sobre o tema, as autoras enfatizaram como as produções audiovisuais contribuíam na construção e disseminação dessas visões, citando como exemplo o filme "Cidade de Deus". Seguindo com a proposta intercultural, as pesquisadoras utilizaram três imagens de mulheres brasileiras, a saber: i) uma colagem a partir das obras de Albert Eckhout; ii) um poster da Embratur em que há uma mulher de biquíni como garota propaganda; e iii) uma foto da "Globeleza", Valéria Valenssa, estrela das vinhetas de carnaval da emissora Rede Globo de televisão de 1990 a 2005. Elas sugeriram que os participantes assistissem o vídeo "Mulher brasileira é só bunda e carnaval?, em seguida, solicitaram a produção de um parágrafo sobre o tema abordado. Essas atividades possibilitaram que os alunos conversassem, também, sobre a temática do machismo e o desrespeito que as mulheres sofrem, enfatizando que essas questões não são apenas dos estrangeiros, mas geral, uma vez que os próprios homens brasileiros também o fazem. Outrossim, os dois alunos estrangeiros reconhecem toda a problemática abordada durante a proposta didática e ratificam que não compactuam com os discursos e os estereótipos feitos acerca da mulher brasileira no exterior, uma vez que, por gostarem do país e por terem tido experiências no Brasil, essas representações, criadas em seus países de origem, foram ressignificadas. Diante disso, as autoras finalizam o estudo defendendo a relevância da temática do material didático elaborado e acreditam que as atividades proporcionaram aos dois alunos estrangeiros vivenciar diferentes dinâmicas em sala de aula, bem como o olhar para os aspectos interculturais que perpassam a aprendizagem de uma língua adicional.

O capítulo "Reflexões sobre práticas de ensino de português para estrangeiros em São Luís do Maranhão" é de autoria de Maria José Nélo, professora da Universidade Estadual do Maranhão. O texto relata uma experiência de ensino de Português como Língua Estrangeira (PLE), ocorrida de junho a julho de 2018, com alunos africanos, oriundos do Senegal, Guiné Equatorial, Nigéria e Serra Leoa, em situação de acolhimento no Maranhão. A autora situa que o curso de ensino de língua portuguesa, variante brasileira, foi realizado logo após vinte e seis africanos serem encontrados à deriva na Baia de São José, próximo a São Luís, em situações precárias, isto é, sem água e sem comida. Os alunos pertencem a diferentes grupos étnicos e eram falantes de duas ou mais línguas, uma vez que haviam sido escolarizados em árabe, alguns em árabe e francês e também em inglês, enquanto alguns eram semianalfabetos. A experiência aqui relatada teve como foco a temática alimentação e culinária regional, explorando características especificas da comida maranhense uma vez que alguns alunos já tinham trabalhado como cozinheiros e devido ao estranhamento do período Ramadã da cultura dos estudantes, isto é, por eles comerem e beberem depois do Pôr do Sol e antes de o Sol nascer, a temática se mostrou pertinente. Para as aulas, os professores utilizaram como material didático o livro "Português do Brasil para refugiados e refugiadas. Pode entrar", do qual o capítulo sete, "Respeitar os diferentes", foi tratado ao longo do curso por abordar questões relacionada ao estudo de vocábulos sobre verduras, frutas e legumes, bem como a presença de diálogos sobre o assunto. 
A temática escolhida, bem como o arcabouço teórico baseado nas reflexões sobre o ensino de língua e de cultura de Geraldi, Almeida Filho, Silveira, DaMatta e Queiroz, possibilitou a realização de atividades que proporcionaram a aprendizagem linguística do português brasileiro e aspectos da cultura do Brasil, de forma especifica, do Maranhão pelos aprendizes. Além disso, os alunos puderam ao longo dos encontros retratarem sobre seus aspectos culturais, no que diz respeito à religião, ao papel do homem na sociedade, sobre o Ramadã, culinária e alimentação, isto é, de aspectos da sua cultura em relação aos do Brasil. Por fim, a autora finaliza que os resultados gerados, a partir da experiência com os alunos em situação de acolhimento, trouxe uma nova perspectiva sobre como realizar o ensino para aqueles que buscam novos horizontes de vida. Outrossim, os resultados demonstraram que a perspectiva intercultural esteve presente ao longo do processo de aprendizagem dos estudantes, pois eles puderam não somente aprender e reconhecer as manifestações culturais dos brasileiros, mas além de tudo, reconhecer os aspectos de sua própria cultura, estando preparados para utilizar comunicativamente a língua portuguesa.

Ao final da primeira parte da coletânea, temos o capítulo intitulado "O ensino de gramática na aula de português como língua estrangeira: opções para um ensino diversificado”, de autoria de Luis Gonçalves, professor da Universidade de Princenton, em New Jersey, Estados Unidos da América. Neste capítulo, as reflexões estão voltadas para o papel e a presença ou a não presença da gramática no processo de ensinoaprendizagem de língua estrangeira, de forma específica para o português. Para tanto, a partir dos postulados teóricos de Krashen, Larsen-Freeman, Pratt, dentre outros, Luis Gonçalves realiza sutilmente um percurso histórico retratando a gramática como foco do ensino de língua estrangeira em meados do século XX e o modo como a comunicação e a interação na língua-alvo ganhou destaque, com o surgimento de novos métodos e abordagens, fazendo com que o ensino de estruturas e aspectos gramaticais não fossem mais abordados da forma que era antes, no viés tradicional, mas por uma abordagem contextual. Assim, o objetivo no processo de ensino-aprendizagem passa a ser o desenvolvimento da competência comunicativa que é realizada a partir da junção de outras competências, ademais da competência gramaticais, a saber: competência discursiva, competência sociolinguística e competência estratégica. Não obstante, o autor, ao tecer suas considerações, afirma que a ausência por completa da gramática é problemático, pois o seu ensino pode ajudar na aprendizagem da língua estrangeira, ratificando a presença gramática nas aulas de uma língua estrangeira, pois ela poderá deixar o processo mais fácil e rápido. Nessa mesma linha de raciocínio, Luis Gonçaves pontua que é necessário abordar a gramática de diversas formas, segundo o autor, "de uma forma cíclica", isto é, a partir de uma diversidade de abordagens, levando em consideração os diferentes estilos de aprendizagem que os discentes possuem, com foco no uso.

Por sua vez, a parte II, compõe trabalhos de variadas abordagens, mas que problematizam questões acerca dos materiais didáticos para o ensino de Português como Língua Estrangeira. O primeiro capítulo, 
apresenta-nos uma discussão a partir de uma proposta de ensino da cultura e língua portuguesa a partir da literatura. No capítulo seguinte, o material didático para o ensino de português para hispanofalantes argentinos é observado com bastante atenção, a partir das dimensões interlinguística e intercultural. O último capítulo dessa parte, e dessa coletânea, coloca em pauta propostas didáticas que possuem caráter humorístico.

Como mencionamos, o capítulo "Ensino de Português como língua estrangeira e literatura: a didatização de materiais autênticos", cuja autoria é de Aparecida Regina Borges Sellan, que é professora, doutora em Língua Portuguesa e pós-doutora em Estudos da Linguagem, destaca a literatura para o ensino da cultura e da língua portuguesa. Nas primeiras linhas, encaramos uma breve discussão acerca das filiações terminológicas para designar o ensino de uma segunda língua, em especial o ensino do português. Ao avançar, a leitura nos revela que Sellan considera as práticas sociais como abordagem pedagógica, ao integrar a interculturalidade como base teórico-metodológica de ensino. Outro ponto de destaque é sua filiação à literatura, ao oferecer o texto literário como aspecto cultural consistente para ensinar e aprender. A seção "Uma conversa ilustrada" é o momento em que apreciamos a proposta de ensino e uma breve discussão. O conto utilizado, "A sociedade”, de Antônio de Alcântara Machado, levantou muita discussão entre os participantes, desde as escolhas lexicais para compor a obra até questões mais amplas de compreensão leitora. Por fim, a leitura do capítulo mostrar que pode ser produtivo o uso do gênero conto para aprendizes de Língua Portuguesa, uma vez que esse gênero, retomando a voz da autora, mostra "a fundação social, histórica, ideológica e cultura do brasileiro" (p. 155).

O capítulo "As dimensões interlinguística e intercultural em livros didáticos de Português para hispanofalantes”, de Florencia Miranda, professora de Cursos de Português na Universidade Nacional de Rosario, na Argentina, doutora e pós-doutora em Linguística. Como o título do capítulo nos sugere, a discussão central se realiza a partir do escrutínio de seis livros didáticos, especificamente produzidos na Argentina e/ou para estudantes argentinos. O foco dessa análise são as menções explícitas e implícitas das concepções do material, em especial, o caráter interlinguístico e intercultural, filiado ao interacionismo sociodiscursivo, na senda teórica de Bronckart (1997). Ao examinar a primeira dimensão, Miranda discute acerca do destinatário do material didático. Ela verificou que há generalização na indicação dos livros aos falantes de espanhol, mas que é possível constatar referências à cidade de Buenos Aires, o que configuraria como indícios implícitos que destinam o livro a um público específico. Questões como o uso de falsos cognatos, de termos e expressões também são observados e destacados, a autora menciona que, na maioria das vezes, aparecem em seções marginalizadas. Já a dimensão intercultural parece seguir um caminho mais preocupante, conforme demonstrou Miranda, ao afirmar que, nos livros, "não se observam [...] comentários sobre aspectos culturais que possam ser comuns no Brasil e na Argentina” (p. 172). Em síntese, o capítulo 
expõe, de forma bastante clara e objetiva, na análise dos livros didáticos, uma série questões que precisam ser discutidas e, sobretudo, revistas.

Em "O dispositivo humorístico no ensino de português como língua estrangeira”, capítulo final, cuja autoria é da organizadora dessa coletânea, Silvia Ines Caneglian Carrilho de Vasconcelos, que, como mencionado no início dessa resenha, é professora, doutora e pós-doutora em Linguística Aplicada. No seu texto, somos conduzidos para uma análise das ocorrências humorísticas para o ensino de português como língua não materna. Logo após a introdução, a autora nos apresenta pesquisas em diversas áreas do conhecimento que têm se preocupado em estudar o humor. Ela ainda completa oferecendo um arcabouço teórico com concepções sobre o riso e o humor, iniciando em Egrácio (2008), Minois (2003), Propp (1992), atravessando, até mesmo, Bakhtin (1999) e Foucault (2002; 2009). Em seguida, Vasconcelos elabora uma discussão sobre o uso da vírgula a partir de uma postagem em uma rede social que satiriza a figura de um político brasileiro. Essas propostas situadas nas práticas midiáticas cotidianas, segundo a autora, “também exercem papel pedagógico" (p. 184). A segunda abordagem apresentada é um episódio de humor construído a partir da dificuldade de articulação palatal em vocábulos que possuem “lh". Para isso, faz menção a um vídeo que destaca um sujeito não falantes de português realizando permutas de sentido em decorrência desse fonema. Caminhando para a conclusão desse capítulo, as palavras da autora, ilustram bem a compreensão que temos da leitura, ao destacar que o cômico e o riso podem "ser um excelente recurso de aprendizado a ser aplicado por professores no ensino de língua portuguesa” (p.187).

Para finalizar, observamos que os dez capítulos se apresentam como um importante empreendimento intelectual necessário para os profissionais da educação, sobretudo aos professores que se dedicam a tarefa de ensinar a Língua Portuguesa como segunda língua. Ressaltamos, ainda, a função social dessa coletânea, pois ao tempo em que apresenta resultados de pesquisas transformam vidas com propostas exitosas. 